\title{
Research Paper: A Comparison of Time Use Patterns and Self-Efficacy Between Mothers of Children With Cerebral Palsy and Mothers of Typically Developing Children
}

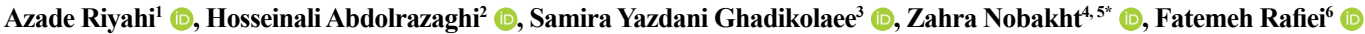 \\ 1. Department of Occupational Therapy, School of Rehabilitation, Arak University of Medical Sciences, Arak, Iran. \\ 2. Department of Hand and Reconsructive Surgery, Sina Hospital, Tehran University of Medical Science, Tehran, Iran \\ 3. Occupational Therapist in Social Welfare Organization, Mazandaran, Iran. \\ 4. Pediatric Neurorehabilitation Research Center, University of Social Welfare and Rehabilitation Sciences, Tehran, Iran \\ 5. Department of Occupational Therapy, University of Social Welfare and Rehabilitation Sciences, Tehran, Iran. \\ 6. Department of Biostatistics and Epidemiology, School of Health, Scientific Research Center, Tehran University of Medical Sciences, Tehran, Iran
}

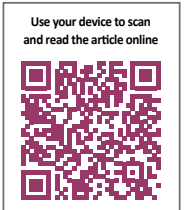

Citation: Riyahi A, Abdolrazaghi H, Yazdani Ghadikolaee S, Nobakht Z, Rafiei F. A Comparison of Time Use Patterns and Self-Efficacy Between Mothers of Children With Cerebral Palsy and Mothers of Typically Developing Children. Iranian Rehabilitation Journal. 2019; 17(4):305-312. http://x.doi.org/10.32598/irj.17.4.305

doi http://dx.doi.org/10.32598/irj.17.4.305

\section{(c) (1) (8)}

Article info:

Received: 15 May 2019

Accepted: 13 Nov 2019

Available Online: 01 Dec 2019

\section{Keywords:}

Cerebral palsy, Self-efficacy,

Time use patterns

\section{ABSTRACT}

Objectives: Comparing time use patterns and self-efficacy in two groups of mothers, including mothers of children with Cerebral Palsy (CP) and mothers of children with typical development, is the main objective of this study.

Methods: This study was carried out in 2017 in Arak, Iran, on 200 mothers. Multiple sources of the evaluation, including Mothers' Time Use Questionnaire and Sherer General Self-efficacy Questionnaire, were used. SPSS v. 22 software was used to analyze the data.

Results: The Mean \pm SD age of children was $4.64 \pm 1.46$ years in the group of children with $\mathrm{CP}$ and $4.64 \pm 1.47$ in the group of children with typical development. Significant differences were found between groups in the amount of time spent in various occupations, including self-care, childcare and household, leisure, rest/sleep, and work. Mothers of children with CP significantly spent a bigger proportion of time on "rest/sleep" and "childcare and household" areas $(\mathrm{P}<0.001)$. However, mothers of children with typical development spent significantly more time in "Self-care" $(\mathrm{P}=0.01)$, "Leisure" $(\mathrm{P}<0.001)$, and "Work" $(\mathrm{P}<0.001)$ areas. Also, significant differences were found between groups in the level of satisfaction.

Discussion: Lower total score of the time use questionnaire in the group of mothers of children with $\mathrm{CP}$ might be because of the nature of limitations and the negative burden of this type of disease in terms of socio-cultural and fewer health system services.

\section{* Corresponding Author:}




\section{Highlights}

- The occupational areas, where the mothers need to be more active to do them, could be limited to other areas like sleep/rest. This leads to an occupational imbalance in their roles and routines.

- Level of satisfaction of time use and general self-efficacy in mothers of children with CP decreased compared to mothers of typically developing children.

\section{Plain Language Summary}

The presence of a child with $\mathrm{CP}$ in the family imposes two pressures upon the family. First, the high cost of treatment that the family has to spend more time on employment and income-generating. Second, spending too much time to care for a child with $\mathrm{CP}$ may have a negative impact on family employment and income-generating. The mother, as the main caregiver, spends her time and energy for caring and doing her child's Activity of Daily Living (ADL) and may ignore her occupational balance in ADL.

\section{Introduction}

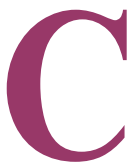

erebral Palsy (CP) is the most common cause of permanent disorders in the development of movement and posture. These permanent disorders are often accompanied by associated disorders, including the disturbances of sensation and perception, cognition, communication, and or seizure [1]. The prevalence of $\mathrm{CP}$ in most developed countries is 2 to 3 per 1000 live births [2]. It was mentioned that children with bilateral spastic CP had the most limitations in their motor function [3]. Children with CP have lower levels of physical activity than other children [4]. Having a child with disabilities causes physical and psychological stress on the family member. Parents of children with CP usually report high levels of stress [5]. Children with CP often have delayed motor development, sensory deficits, and cognitive delays, which can bring many challenges for their caregivers [6].

Evidence suggests that mothers are mostly the main caregiver of children [7-9]. Some interventions impact parents' physical and emotional health $[10,11]$. Two studies found that some mothers feel worthless and blame themselves for their children's problems; thus, they experience higher levels of stress, which can lead to a decrease in their mental health and quality of life $[12$, 13]. Approximately, $85 \%$ of the main caregivers of children with CP are mothers [14]. The time required for the care of children with CP can impact mothers' occupation, including leisure activities and social activities. Dalvand, Rassafiani, and Hosseini found that almost 30\% of the mothers reported reduced allocated time in vocational activities because of childcare responsibilities [10].Not having a balanced time use pattern can lead to mothers' depression, feelings of incompetence in parenting, poor emotional parent-child relationships, and higher levels of stress in the family [15].

Occupational Therapy Practice Framework introduced 8 occupation areas, in which a person may participate during a day [16]. These domains are playing, ADL, instrumental activities of daily living, education, sleep/ rest, leisure, work, and social participation. Occupational therapy models emphasize the balance among different areas of life (self-care, sleep and rest, productivity, and leisure) [17]. Having balanced time use is defined as a proper and useful organization of everyday activities of an individual [18].

In some cases, to promote health and quality of life, changing time use patterns is needed [19]. Self-efficacy is one of the health-related variables that may be impaired in this group of mothers. Self-efficacy is defined as a person's judgment of his or her ability in performing activities to achieve specific goals [20]. High self-efficacy in mothers enhances their sufficiency and flexibility in different situations; while, mothers who have lower levels of self-efficacy often experience more challenges in their life [21]. Mothers of children with disabilities are more likely to have mental health problems than other mothers [13]. Because mothers of children with CP have less time to consider their own affairs such as leisure time and work, they are likely to have low efficacy in their stressful life experiences [22].

However, in assessing mothers with children with attention deficit hyperactivity disorder, there were no significant differences between mothers of these children 
and mothers of children with typical development [23]. Time use is heavily influenced by culture [24]. For example, Gevir et al. did not find a significant difference in the time allocation of different occupational areas [25]. Whereas, in other studies, time use differences have been reported in mothers of children with autism, children with $\mathrm{CP}$, and mothers of typically developing children $[11,14]$. Here, we increased the number of participants to achieve a clear picture compared with the previous studies. The main aim of this study was to compare time use patterns and self-efficacy in mothers of children with $\mathrm{CP}$ and mothers of children with typical development.

\section{Methods}

To compare time use patterns and self-efficacy in mothers of children with CP and mothers of children with typical development, a cross-sectional survey with matched controls was designed. It seems that there is limited evidence about the time use patterns of mothers of typically developing children in Iran compared with mothers of children with CP. As an instance, Rassafiani et al. [14] found that mothers of typically developing children spent a big proportion of time on household activities and a small proportion of time on paid work. But, this evidence is limited; so, we decided to have a group of mothers of typically developing children for comparison.

\section{Participants}

The convenient sampling method was used to include 200 mothers (100 with typically developing children and 100 with children with CP) in this cross-sectional study. The inclusion criteria included 1) mothers able to read and write, 2) mothers aged 20 to 50 years, 3) children aged between 2 and 12 years, and 4) mothers with no severe depression. Mothers of children with treatmentresistant seizures and mothers, who lived alone, were excluded from the study. Informed written consent was received from the caregivers. The study was approved by the Ethics Committee for Human Experiments of the Arak University of Medical Sciences (ID: IR.ARAKMU. REC.1396.78).

\section{Instruments}

\section{Mother's Time Use Questionnaire}

An authored designed demographic questionnaire was used to collect the participants' characteristics. Time use patterns of mothers and their satisfaction with time use management was achieved by completing Mother's Time Use Questionnaire [25]. The questionnaire includes activities in 6 categories, including self-care, child-related activities \& housework, sleep/rest, leisure activities, work, and social participation [25]. Time log tables and general questions about time management of the Mothers Time Use Questionnaire are reported in this study. The time log section asked mothers to report typical day activities from morning to midnight. The test-retest reliability coefficient of this questionnaire was between 0.78 and $0.89[14,25]$.

\section{Sherer general self-efficacy inventory}

The Sherer General Self-efficacy Questionnaire was used to compare self-efficacy in two groups. This questionnaire consists of 17 items and each item uses a Likert scale from 1 to 5 points. It includes items like "when I make plans, I am certain I can make them work" or "If I cannot do a job the first time, I keep trying until I can". The maximum score is 87 and the minimum one is 17 . The reliability of this scale in the study of Arabian et al. was $0.91[20,26,27]$.

\section{Depression, anxiety, and stress scale}

This Depression, Anxiety, and Stress Scale (DASS-21) consists of 42 phrases about symptoms of negative emotions [28]. Depression, Anxiety, and Stress constitute 3 subscales of this scale. The short form (DASS-21) with each subscale consisting of 7 questions was used. The participant was asked to rate the intensity of the symptom in each statement based on what she experienced during the last week from 0 (without the experience of the intended symptom) to 3 (very high experience of the symptom). In the end, the obtained score was multiplied by 2 , in which scores from 0 to 9 were normal, 10 to 13 indicated mild depression, 14 to 20 indicated moderate depression, 21 to 27 indicated severe depression, and scores more than 28 indicated very severe depression. In this research, a depression subscale was used. This instrument has a reliability coefficient of 0.84 for depression scale, 0.89 for anxiety, and 0.9 for stress; its Cronbach's alpha coefficient for depression is 93.03 [28-30].

\section{Data collection}

Mothers of children with CP were selected from the clients of occupational therapy clinics and mothers of children with typical development were selected from kindergarten or primary schools. Mothers who were eligible to be included were requested to sign an informed consent and, then, they were asked to consider a typical day from 5 am to $12 \mathrm{pm}$ and complete the questionnaire. After they completed the Time Use Questionnaire, they 
were also asked to complete the Sherer General Self-efficacy questionnaire. An occupational therapist (Third author) helped the mothers to complete the questionnaires.

\section{Data analysis}

SPSS V. 22 software was used to analyze the data. Chisquare and Fisher's exact tests were used to compare the gender of the children in the two groups and the economic level of the families, respectively. Independent ttest was used for the age of mothers and children and the number of children in the family. Independent t-test and Mann-Whitney test were used to compare the time use categories. In all cases, the significance level was considered as $\mathrm{P}=0.05$.

\section{Results}

The Mean \pm SD age of the group of children with $\mathrm{CP}$ and the group of children with typical development was $4.64 \pm 1.46$ and $4.64 \pm 1.47$ years, respectively. In the group of typically developing children, 27 (27\%) were male and $73(73 \%)$ were female, but in the group of children with CP, 35 (35\%) were male and 65 (65\%) were female; $85 \%$ of children with CP were mostly distributed in levels II, III, and IV of Gross Motor Function Classification System (GMFCS). Table 1 presents the demographic characteristics of the participants.

In Table 2, the time allocation, self-efficacy, and satisfaction rate of time management in the mothers of the two groups have been addressed. In the occupational areas between the two groups, there was a significant difference in the time spent in each of the 5 areas, except for social participation. There was no significant difference in selfefficacy, but this difference was significant in the level of satisfaction between the two groups (Table 3).

\section{Discussion}

The occupational balance will be created when the individual devotes a reasonable amount of time to each aspect of her occupations. Mothers who spend a significant amount of their daily time in taking care of a child with a disability are at risk of disruption of this balance [31]. In this study, the results showed that more responsibilities in caring for a child with $\mathrm{CP}$ along with ordinary other roles can cause time pressure for the mother. When the mothers are forced to take the role of caregiver in addition to their other responsibilities, they would inevitably have less time allocating to occupations like taking care of themselves, their work, and leisure time as McCann, Bull, and Winzenberg indicated in their systematic review [32].

The participants in the group of children with $\mathrm{CP}$ compared with mothers who had typically developing children spent more time on sleep/rest. So, the more caregiving is needed and the higher the degree of disability of the child is, the more restrictions, pressure, fatigue, and exhaustion are imposed upon them; thus, increasing the hours of sleep and rest can be expected [33]. When

Table 1. Distribution of demographic information in mothers of children with $\mathrm{CP}$ and mothers of children with typical development

\begin{tabular}{|c|c|c|c|c|}
\hline & Item & $\begin{array}{l}\text { Mothers of Children } \\
\text { With CP }\end{array}$ & $\begin{array}{c}\text { Mothers of Children With Typical } \\
\text { Development }\end{array}$ & $\mathbf{P}$ \\
\hline \multirow{3}{*}{ Education level, n (\%) } & Primary and middle school & 38 & 8 & - \\
\hline & High school & 41 & 38 & - \\
\hline & University degree & 21 & 54 & - \\
\hline \multirow{3}{*}{ Job status, n (\%) } & Full-time & 0 & 9 & - \\
\hline & Part-time & 12 & 18 & - \\
\hline & No job & 88 & 73 & - \\
\hline \multirow{3}{*}{ Economic level of family } & High & 2 & 6 & \multirow{3}{*}{$0.31 *$} \\
\hline & Average & 90 & 84 & \\
\hline & Low & 8 & 10 & \\
\hline \multicolumn{2}{|c|}{ Age (y), Mean $\pm S D$} & $31.05 \pm 6.77$ & $31.83 \pm 6.85$ & $0.41 * *$ \\
\hline
\end{tabular}


Table 2. Distribution of demographic information in children with $\mathrm{CP}$ and children with typical development

\begin{tabular}{|c|c|c|c|c|}
\hline & Item & Children With CP & Children With Typical Development & $\mathbf{P}$ \\
\hline \multirow{3}{*}{ Sex, n (\%) } & Female & 65 & 73 & \multirow{3}{*}{$0.22 * * *$} \\
\hline & & & & \\
\hline & Mail & 35 & 27 & \\
\hline \multirow{6}{*}{ GMFCS*, n (\%) } & 1 & 4 & -- & - \\
\hline & $\|$ & 33 & -- & - \\
\hline & III & 23 & -- & - \\
\hline & IV & 20 & 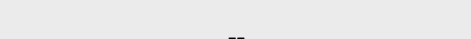 & 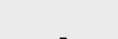 \\
\hline & V & 10 & - & - \\
\hline & Missing & 1 & -- & - \\
\hline \multirow{7}{*}{ MACS**, n (\%) } & 1 & 17 & -- & - \\
\hline & $\|$ & 38 & -- & - \\
\hline & III & 22 & -- & - \\
\hline & & & & \\
\hline & IV & 19 & -- & - \\
\hline & V & 3 & -- & - \\
\hline & Missing & 1 & -- & - \\
\hline \multicolumn{2}{|c|}{ Age (y), Mean $\pm S D$} & $4.64 \pm 1.46$ & $4.64 \pm 1.47$ & $0.96^{* * * *}$ \\
\hline
\end{tabular}

Notes: *Gross Motor Function Classification System; **Manual Ability Classification System

Iranian Rehabilitation „ourna

*** Chi-Square test, ${ }^{* * * *}$ independent t-test

mothers spend excessive time on one occupation like sleeping causes, other areas are neglected. In other studies such as Crowe et al. mothers of children with dis- abilities spent a big proportion of time on taking care of children. Then, they could not consider reasonable time

Table 3. Comparing allocated time (in hours) spent on six various activities, satisfaction and self-efficacy scores in both groups

\begin{tabular}{|c|c|c|c|}
\hline \multirow{2}{*}{ Variable } & \multicolumn{2}{|c|}{ Mean $\pm S D$} & \multirow{2}{*}{ P* } \\
\hline & Mothers of Children With CP & Typically Developing Children Mothers & \\
\hline Self-care & $1.47 \pm 1.25$ & $1.91 \pm 1.02$ & 0.01 \\
\hline Rest /sleep & $5.36 \pm 1.25$ & $4.67 \pm 1.23$ & $<0.001$ \\
\hline Childcare \& household & $9.32 \pm 2.29$ & $4.52 \pm 3.99$ & $<0.001$ \\
\hline Leisure & $1.42 \pm 1.31$ & $3.43 \pm 2.4$ & $<0.001$ \\
\hline Work & $0.78 \pm 2.42$ & $2.92 \pm 4.5$ & $<0.001$ \\
\hline Social participation & $0.61 \pm 0.76$ & $0.71 \pm 0.98$ & 0.67 \\
\hline Self-efficacy & $45.52 \pm 5.76$ & $46.95 \pm 7.21$ & 0.1 \\
\hline Satisfaction & $2.89 \pm 0.51$ & $3.16 \pm 0.52$ & $<0.001$ \\
\hline
\end{tabular}

*Mann-Whitney

Iranian Rehabilitation \ourna 
for their own leisure time [34-36]; similar results were achieved by Rassafiani et al. [14].

According to the findings of the study, the areas of leisure, work, and self-care also differed significantly between mothers in the two groups. This finding was consistent with some of the previous studies and contradictory with others $[14,25,34]$. One of the reasons for the difference between the findings of this study and the research conducted by Rassafiani et al. can be related to the place of research. A study by Rassafiani et al. was conducted in the capital city with more capabilities and facilities for mothers, while the current study was conducted in one of the provincial centers.

These findings can emphasize the importance of the context of people's lives as an important factor in spending time. Failure to pay more attention to refreshing occupational areas such as leisure or areas, where mothers can pay more attention to their interests and needs (work and self-care), has led to a significant difference in terms of satisfaction with time management between the two groups; it contradicted the results of Gevir et al. [25], who used same tools to measure satisfaction. In the present study, in all 3 areas (leisure, self-care, and work) mothers of children with $\mathrm{CP}$ spend less time, which could eventually be one of the reasons for their dissatisfaction with spending time on various occupations throughout the day. In the research by Gevir et al., there were no significant differences between the two groups in this area. Satisfaction is an internal matter and can, therefore, play an important role in the mental and physical health of individuals.

The second part of the findings of the study was about self-efficacy, in which no significant difference was found between the mothers in the two groups. Some previous studies believe that caring for children with disabilities, such as CP, can cause psychological problems in addition to placing more time stress on mothers [34, 37]. In this study, mothers of typically developing children had better self-efficacy, but this difference was not so obvious. Children's broad age spectrum may be one of the reasons for this indifference. Mothers, over time, are very likely to learn how to cope with problems.

Children in this study were 2 to 12 years old. Another reason to be noted is that the mothers of typically developing children also did not score a high self-efficacy score. The maximum score in Sherer's general self-efficacy questionnaire is 87 ; the average score of mothers of children without a disability was less than half of the maximum score. It seems that all mothers participating in this study had a low level of self-efficacy, which requires more examination of mothers, regardless of having a child with a disability. The lack of self-efficacy difference between the two groups of mothers could also be considered as a reason for non-difference in the area of social participation. Social participation is defined as the desired engagement in community and family activities [16]. Since the probability of confronting new conditions in the community is much more than family circumstances and given the low level of self-efficacy, mothers prefer to participate less in social affairs.

The comparison of the two groups was limited to the working days of the week; so, possibly collecting timeuse data on weekends and holidays would look different. Other limitations did not consider the level of intelligence and cognition of children in the two groups of children. Having a low cognitive level can provide more burden care for mothers. The results of this study cannot be generalized to mothers of children with other disabilities. Another limitation of the study was the lack of access to appropriate distribution in some types of population. A suggestion that can be considered for future studies is the investigation of assistance and participation of other family members and their impact on patterns of use of mothers. The use of tools that specifically address maternal self-efficacy can provide more information about the mothers' maternal role.

The presence of a child with $\mathrm{CP}$ in the family imposes two pressures upon the family. First, the high cost of treatment that the family has to spend more time on employment and income-generating. Second, spending too much time to care for a child with CP may have a negative impact on family employment and income-generating. The mother, as the main caregiver, spends her time and energy for caring and doing her child's ADL and may ignore her occupational balance in ADL.

This study was a prerequisite for paying attention to improve the quality of services for caregivers and increase social support for caregivers; it may ultimately lead to the development and design of efficient and effective training programs for caregivers to improve their time use patterns and their efficiency. Also, the results of the research can be used to train caregivers to balance their roles and routines.

\section{Conclusion}

The results of the study showed that the occupational areas, where the mothers need to be more active to do them, could be limited to other areas like sleep/rest. It 
reduces the level of satisfaction of time use and general self-efficacy in mothers of children with CP compared to the mothers of typically developing children.

\section{Ethical Considerations}

\section{Compliance with ethical guidelines}

All ethical principles were considered in this article. The participants were informed about the purpose of the research and its implementation stages; they were also assured about the confidentiality of their information; Moreover, They were allowed to leave the study whenever they wish, and if desired, the results of the research would be available to them.

Funding

This research did not receive any specific grant from funding agencies in the public, commercial, or not-forprofit sectors.

\section{Authors' contributions}

All authors contributed in preparing this article.

\section{Conflict of interest}

The authors declared no conflict of interest.

Acknowledgments

We would like to acknowledge all participants, including mothers of children with $\mathrm{CP}$ and mothers of typically developing children.

\section{References}

[1] Bax M, Goldstein M, Rosenbaum P, Leviton A, Paneth N, Dan B, et al. Proposed definition and classification of cerebral palsy, April 2005. Developmental Medicine and Child Neurology. 2005; 47(8):571-6. [DOI:10.1017/S001216220500112X] [PMID]

[2] Cans C. Surveillance of cerebral palsy in Europe: A collaboration of cerebral palsy surveys and registers. Developmental Medicine \& Child Neurology. 2000; 42(12):816-24. [DOI:10.1111/j.1469-8749.2000.tb00695.x]

[3] Soleimani F, Vameghi R, Rassafiani M, Akbar Fahimi N, Nobakht Z. Cerebral palsy: Motor types, gross motor function and associated disorders. Iranian Rehabilitation Journal 2011; 9:21-31.
[4] Zwier JN, Van Schie PE, Becher JG, Smits D-W, Gorter JW, Dallmeijer AJ. Physical activity in young children with cerebral palsy. Disability and Rehabilitation. 2010; 32(18):1501-8. [DOI:10.3109/09638288.2010.497017] [PMID]

[5] Ketelaar M, Volman M, Gorter J, Vermeer A. Stress in parents of children with cerebral palsy: What sources of stress are we talking about? Child: Care, Health and Development. 2008; 34(6):825-9. [DOI:10.1111/j.1365-2214.2008.00876.x] [PMID]

[6] Riyahi A, Rasafiyani M, Akbar Fahimi N, Karimloo M. Reliability of the Persian Version of Manual Ability Classification System (MACS) Between Parents and Therapists in Children with Cerebral Palsy. Journal of Rehabilitation. 2012; 12(4):1421.

[7] Craig L, Mullan K. How mothers and fathers share childcare: A cross-national time-use comparison. American Sociological Review. 2011; 76(6):834-61. [DOI:10.1177/0003122411427673]

[8] Hess CR, Teti DM, Hussey-Gardner B. Self-efficacy and parenting of high-risk infants: The moderating role of parent knowledge of infant development. Journal of Applied Developmental Psychology. 2004; 25(4):423-37. [DOI:10.1016/j.appdev.2004.06.002]

[9] Roeters A, Gracia P. Child care time, parents' well-being, and gender: Evidence from the American time use survey. Journal of Child and Family Studies. 2016; 25(8):2469-79. [DOI:10.1007/s10826-016-0416-7] [PMID] [PMCID]

[10] Dalvand H, Rassafiani M, Hosseini SA. Handling in the Children with Cerebral Palsy: A Review of Ideas and Practices (A Literature Review). Journal of Rehabilitation. 2013; 13(5):8-17.

[11] Mohammadpour M, Rassafiani M, Ahmadi Khjugh M, Behnia F, Haghgoo H, Biglarian A. Comparing the time-use of mothers with autistic children with that of mothers with healthy ones. Journal of Research in Rehabilitation Sciences 2014; 10(1):182-92.

[12] Riyahi A, Fatehi F, Rassafiani M, Moradzadeh R. Parenting Role's Tasks as Parents of Healthy and Disabled Children. International Journal of Pediatrics. 2017; 5(9):5779-87.

[13] Leahy-Warren P, McCarthy G. Maternal parental self-efficacy in the postpartum period. Midwifery. 2011; 27(6):802-10. [DOI:10.1016/j.midw.2010.07.008] [PMID]

[14] Rassafiani M, Kahjoogh MA, Hosseini A, Sahaf R. Time Use in Mothers of Children with Cerebral Palsy: A Comparison Study. Hong Kong Journal of Occupational Therapy. 2012; 22(2):70-4. [DOI:10.1016/j.hkjot.2012.11.001]

[15] Riyahi A, Yazdani Ghadikolaee S, Kolagar M, Azami Sarukolaii A, Abdolrazaghi H, Rafiei F, et al. Comparing the Parenting Role Tasks in Parents of Children with Mental/ Physical Disabilities. International Journal of Pediatrics. 2017 5(6):5079-89.

[16] Roley S, Delany JV, Barrows C, Honaker D, Sava D, Talley V. Occupational therapy practice framework: Domain and process. American Journal of Occupational Therapy. 2008; 62(6):625-83. [DOI:10.5014/ajot.62.6.625] [PMID]

[17] Wagman P, Håkansson C, Jonsson H. Occupational balance: A scoping review of current research and identified knowledge gaps. Journal of Occupational Science. 2015; 22(2):160-9. [DOI:10.1080/14427591.2014.986512] 
[18] Backman CL. Occupational balance: Exploring the relationships among daily occupations and their influence on well-being. Canadian Journal of Occupational Therapy. 2004; 71(4):202-9. [DOI:10.1177/000841740407100404] [PMID]

[19] Larson EA. The time of our lives: The experience of temporality in occupation. Canadian Journal of Occupational Therapy. 2004; 71(1):24-35. [DOI:10.1177/0008417404071001 07] [PMID]

[20] Najafi M, Foladjang M. [The relationship between self-efficacy and mental health among high school students(Persian)] Daneshvar Raftar. 2007; 14(22):69-81

[21] Jones TL, Prinz RJ. Potential roles of parental self-efficacy in parent and child adjustment: A review. Clinical Psychology Review. 2005; 25(3):341-63. [DOI:10.1016/j. cpr.2004.12.004] [PMID] [PMCID]

[22] Guillamón N, Nieto R, Pousada M, Redolar D, Muñoz E, Hernández E, et al. Quality of life and mental health among parents of children with cerebral palsy: The influence of selfefficacy and coping strategies. Journal of Clinical Nursing. 2013; 22(11-12):1579-90. [DOI:10.1111/jocn.12124] [PMID]

[23] Gohari Z, Dehghani F, Rajabi G, Mahmoudi-Gharaei J. Parenting self efficacy in mothers of children with attention deficit hyperactivity disorder vs. normal children. Iranian Journal of Psychiatry. 2012; 7(2):57-60.

[24] VanLeit B, Crowe TK. Outcomes of an occupational therapy program for mothers of children with disabilities: Impact on satisfaction with time use and occupational performance. American Journal of Occupational Therapy. 2002; 56(4):40210. [DOI:10.5014/ajot.56.4.402] [PMID]

[25] Gevir D, Goldstand S, Weintraub N, Parush S. A comparison of time use between mothers of children with and without disabilities. OTJR: Occupation, Participation and Health. 2006; 26(3):117-27. [DOI:10.1177/153944920602600305]

[26] Arabian A, Khodapanahi Mk, Heydari M, Saleh Sb. Relationships between self efficacy beliefs, mental health and academic achievement in colleagues. Journal of Psychology. 2005; 8(4):360-71.

[27] Asgharnejad T, Ahmadi Dm, Farzad Ve, Khodapanahi Mk Psychometric properties of Sherer's general self-efficacy scale. Journal of Psychology. 2006; 10(3):262-74

[28] Asgharimoghadam M, Saed F, Dibajnia P, Zangeneh J. [Preliminary evaluation of the validity and reliability of the Depression, Anxiety and Stress Scales (DASS) in non-clinical samples (Persian)]. Daneshvar Raftar. 2008; 1(31):23-38.

[29] Brown TA, Chorpita BF, Korotitsch W, Barlow DH. Psychometric properties of the Depression Anxiety Stress Scales (DASS) in clinical samples. Behaviour Research and Therapy. 1997; 35(1):79-89. [DOI:10.1016/S0005-7967(96)00068-X]

[30] Henry JD, Crawford JR. The short-form version of the Depression Anxiety Stress Scales (DASS-21): Construct validity and normative data in a large non-clinical sample. British Journal of Clinical Psychology. 2005; 44(2):227-39. [DOI:10.1348/014466505X29657] [PMID]

[31] McCann D, Bull R, Winzenberg T. The daily patterns of time use for parents of children with complex needs: A systematic review. Journal of Child Health Care. 2012; 16(1):2652. [DOI:10.1177/1367493511420186] [PMID]
[32] Leiter V, Krauss MW, Anderson B, Wells N. The consequences of caring: Effects of mothering a child with special needs. Journal of Family Issues. 2004; 25(3):379-403. [DOI:10.1177/0192513X03257415]

[33] Cantekin I, Kavurmacı M, Tan M. An analysis of caregiver burden of patients with hemodialysis and peritoneal dialysis. Hemodialysis International. 2016; 20(1):94-7. [DOI:10.1111/ hdi.12311] [PMID]

[34] Crowe TK, Florez SI. Time use of mothers with school-age children: A continuing impact of a child's disability. American Journal of Occupational Therapy. 2006; 60(2):194-203. [DOI:10.5014/ajot.60.2.194] [PMID]

[35] Crowe TK, Michael HJ. Time use of mothers with adolescents: A lasting impact of a child's disability. OTJR: Occupation, Participation and Health. 2011; 31(3):118-26. [DOI:10.3928/15394492-20100722-01]

[36] Curran A, Sharples P, White C, Knapp M. Time costs of caring for children with severe disabilities compared with caring for children without disabilities. Developmental Medicine and Child Neurology. 2001; 43(8):529-33. [DOI:10.1017/ S0012162201000962] [PMID]

[37] Sawyer MG, Bittman M, La Greca AM, Crettenden AD, Harchak TF, Martin J. Time demands of caring for children with autism: What are the implications for maternal mental health? Journal of Autism and Developmental Disorders. 2010; 40(5):620-8. [DOI:10.1007/s10803-009-0912-3] [PMID] 